Original Research Paper

\title{
Molecular Detection of Follicle Stimulating Hormone Receptor Polymorphisms and Luteinizing Hormone Gene Variations in Primary and Secondary Iraqi Infertile Women
}

\author{
${ }^{1}$ Noor Basim Naser, ${ }^{1}$ Dr. Ezeddin Atia Albayyar and ${ }^{2}$ Dr. Susan Abed Zaidan \\ ${ }^{1}$ Department of Biology, University of Anbar, Collage of Science, Iraq \\ ${ }^{2}$ University of Anbar, Collage of Medicine, Iraq
}

Article history

Received: 17-09-2018

Revised: 24-09-2018

Accepted: 14-11-2018

Corresponding Author:

Noor Basim Naser

Department of Biology,

University of Anbar, Collage of Science, Iraq

Email: asalafahad@gmail.com

\begin{abstract}
The current study aimed to determine the role of hormonal disturbances in infertility, moreover assessing variations at the molecular level that could affect this disease. The study examined 90 blood samples, 30 patients with primary infertility, 30 patients with secondary infertility and 30 healthy women as control. FSH and LH were measured using Electrochemiluminescence assay. DNA was isolated for molecular detection of polymorphisms at the nucleotide level (rs6166 and rs28928870) in FSHR gene using ASO PCR technique and identification mutations in LH gene using PCR technique followed by sequencing. The results showed no significant differences in FSH levels $(6.95 \pm 4.55 \mathrm{mIU} / \mathrm{ml}$, $5.48 \pm 4.64 \mathrm{mIU} / \mathrm{ml}$ and $5.52 \pm 3.07 \mathrm{mIU} / \mathrm{ml}$ ) between control, primary and secondary respectively, while LH showed significant differences between primary and secondary groups $(14.23 \pm 12.17 \mathrm{mIU} / \mathrm{ml}$ and $8.54 \pm 5.62$ $\mathrm{mIU} / \mathrm{ml}$ ) respectively. A significant positive correlation was found between FSH and LH. The molecular study showed different polymorphisms at different positions in LH gene detected by sequencing. Regarding FSHR polymorphisms our results showed that the OR $(95 \% \mathrm{CI})$ for AA and AG genotypes of Asn680Ser polymorphism (rs6166) was 3.32 (0.14-78-49) and $1.00(0.06-15.99)$ respectively for primary infertility. Moreover, the OR $(95 \% \mathrm{CI})$ for $\mathrm{AA}$ and $\mathrm{AG}$ of this polymorphism was 1.00 (0.07-17.59) and $3.0(0.13-70.59)$ respectively for secondary infertility. While regarding Thr449Ile (rs28928870) only the wild type was detected in the studied group. In conclusion, AG genotype ofAsn680Ser is more prevalent in the Iraqi studied women. Furthermore, A allele is a risk factor for the disease as the (OR: 1.49 95\% CI: $0.44-5.03$ ) for the primary group and (OR: $1.2295 \%$ CI: 0.35-4.23) for secondary group.
\end{abstract}

Keywords: Infertility, FSH, LH, Polymorphisms

\section{Introduction}

Infertility according to the World Health Organization is "a disease of the reproductive system defined by the failure to achieve a clinical pregnancy after 12 months or more of regular unprotected sexual intercourse" (Zegers-Hochschild et al., 2009). It has been estimated that infertility of couples affect $10-15 \%$ of the general population (Ekwere et al., 2007). Infertility in women can be divided into two groups; primary infertility in couples who have never been conceived and secondary infertility that is related to couples who have previously conceived and have difficulty in conceiving again. This group includes full term pregnancy and also miscarriages, abortions etc. (Sharma et al., 2011). Previous studies discovered number of causes of female infertility and the most important ones were menstrual disorders, impaired ovulation, uterine causes, tubal factors and cervical causes (Masoumi et al., 2015). The primary fertility hormones that affect the reproductive function are follicle stimulating hormone and luteinizing hormone. These gonadotropins are the key drivers of the menstrual cycle. Follicular growth and maturation depends on the joint action between these gonadotropins. FSH is well 
known as it is the responsible of ovarian follicle growth and maturation. LH main action is ovulation induction and acts on theca cells to induce androgen substrate for estrogen conversion by the aromatase system (Filicori and Cognigni, 2001). In the past years different gene mutations or polymorphisms had been identified that result in or are linked to infertility. Thus the causes of this disease could be at the molecular level or even inherited (Matzuk and Lamb, 2008). FSH receptor is important and crucial for FSH biological activity. Thus Identification different activating and inactivating mutations and SNPs in the FSHR gene and associate them with some respective phenotypes such as PCOS, Premature Ovarian Failure POF and amenorrhea suggest that receptor function is impaired resulting in infertility. These mutations or SNPs could alter the receptor structure and result in the inability of binding between hormone and its receptor (Desai et al., 2013). On the other hand LHB G1502A polymorphism can be involved in the predisposition to infertility and minimal/mild endometriosis-associated infertility, although endometriosis might be only a coincidental finding along with infertility (Mafra et al., 2010). This study aimed to evaluate FSH and LH levels among infertile and fertile women and further investigation of the molecular changes in DNA bands of LH gene and detection of two SNPs in FSHR gene (rs6166) and (rs28928870).

\section{Materials and Methods}

A case-control study was conducted in Fallujah city involved a total of 90 women. They were divided into three groups; 30 women with primary infertility, 30 with secondary infertility and 30 as control group. $5 \mathrm{ml}$ of venous blood was collected for both hormonal analysis and molecular detection.

FSH and LH levels were measured by using electrochemiluminscence assay. $24 \mu \mathrm{L}$ and $20 \mu \mathrm{L}$ of sample for both FSH and LH were used for determination. The Elecys assay uses the principle of the sandwich test

DNA was extracted from leukocyte and amplified with primers in Table 1 using conventional PCR for LH gene that was further sequenced and Allele Specific Oligonucleotide PCR technique for FSHR gene polymorphisms. The PCR end product was then electrophoresed with $2 \%$ agarose gel and the bands were visualized under UV light.

Statistical Analysis: Statistical analysis was used depending on Complete Randomized Design (CRD) and by using means comparison with Least Significant Difference (L.S.D.) test. Correlation coefficient and relation between variables was also measured by using ready SPSS program version 23. Genotype frequency and allele frequency were determined using Winpepi compare 2 .
Table 1: Primers used in this study

\begin{tabular}{ll}
\hline Gene & Primer \\
\hline FSHR rs6166 & Fw.t:GGGACAAGTATGTAAGTGGAACCTT \\
& Fm:GGGACAAGTATGTAAGTGGAACCTC \\
& R:ACTGTGTCCAAAGCAAAGAT \\
FSHR & Fw.t:AGCTCACTGGCAAAGACTG \\
rs28928870 & Fm: AGCTCACTGGCAAAGACTA \\
& R:GTGATCCTAACTACCAGCCA \\
LH 1 & F:GGATGGAGATGCTCCAGGTA \\
& R:CCTGAGGTGGCAGCATCT \\
LH 2 & F:CCTCAGGCACATGCTCATT \\
& R:CCTTTATTGTGGGAGGATCG \\
\hline
\end{tabular}

\section{Results}

Table 2 shows the mean \pm S.D for FSH and $\mathrm{LH}$ concentrations. Mean \pm S.D for FSH was $6.95 \pm 4.55$ $\mathrm{mIU} / \mathrm{ml}, 5.48 \pm 4.64 \mathrm{mIU} / \mathrm{ml}$ and $5.52 \pm 3.07 \mathrm{mIU} / \mathrm{ml}$ in control, primary and secondary group respectively. No significant differences were found in FSH level among the three groups. Mean \pm S.D for $\mathrm{LH}$ was $10.36 \pm 12.62$ $\mathrm{mIU} / \mathrm{ml}, 14.23 \pm 12.17 \mathrm{mIU} / \mathrm{ml}$ and $8.54 \pm 5.62 \mathrm{mIU} / \mathrm{ml}$ in control, primary and secondary groups respectively. There were not significant differences in LH levels among the three groups; except for primary and secondary group where the mean difference was statically significant with higher Mean \pm S.D was in primary group $(\mathrm{p}=0.037)$. FSH showed significant positive correlation with LH (.496 $6^{* *}$ ) (Data not shown).

Results of direct sequencing for LH gene showed different polymorphisms in different positions. G/A polymorphism which is a transition mutation had the higher percent of frequency. Both $\mathrm{C} / \mathrm{T}$ at position 159 and $\mathrm{G} / \mathrm{A}$ at positions $(67,135$ and 230$)$ were found in control and primary groups and associated with elevated LH levels, Table 3.

The separated bands of FSHR gene for Asn680Ser polymorphism are shown in Fig. 1. The genotype frequency for rs6166 between control and primary group, then between control and secondary group has been calculated. FSHR polymorphic variant (AA, AG and $\mathrm{GG})$ were $(0,90 \%$ and $10 \%)$ respectively in the control group and were $(10 \%, 90 \%$ and 0$)$ respectively in the primary group. The Odd Ratio (OR) for AA and AG genotypes were (OR:3.32 95\%CI:0.14-78.49) and (OR:1.00 95\%CI:0.06-15.99) respectively I primary infertility group. The frequency of allele $A$ and $G$ in control group were (45\%) and (55\%) respectively, while the frequencies in primary group were $(55 \%)$ and $(45.00 \%)$ respectively. The OR for allele A was (OR: 1.49 95\%CI:0.44-5.03).

Regarding the comparing between control and secondary group; the polymorphic variant (AA, AG and GG) were $(0,100 \%$ and 0$)$ respectively. The OR for the AG genotype was (OR: 3.0 95\%CI:0.13-70.59). The frequency of allele $\mathrm{A}$ and $\mathrm{G}$ were $(50 \%)$ and $(50 \%)$ respectively in the secondary group. The OR for allele A was (OR: 1.22 95\%CI:0.35-4.23) Table 4. 


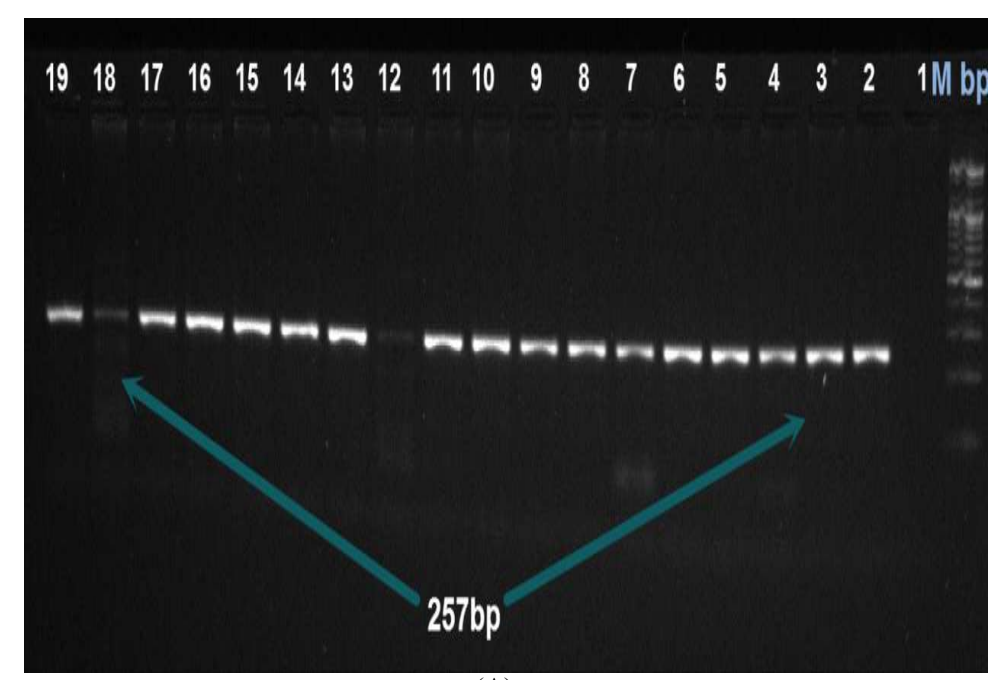

(A)

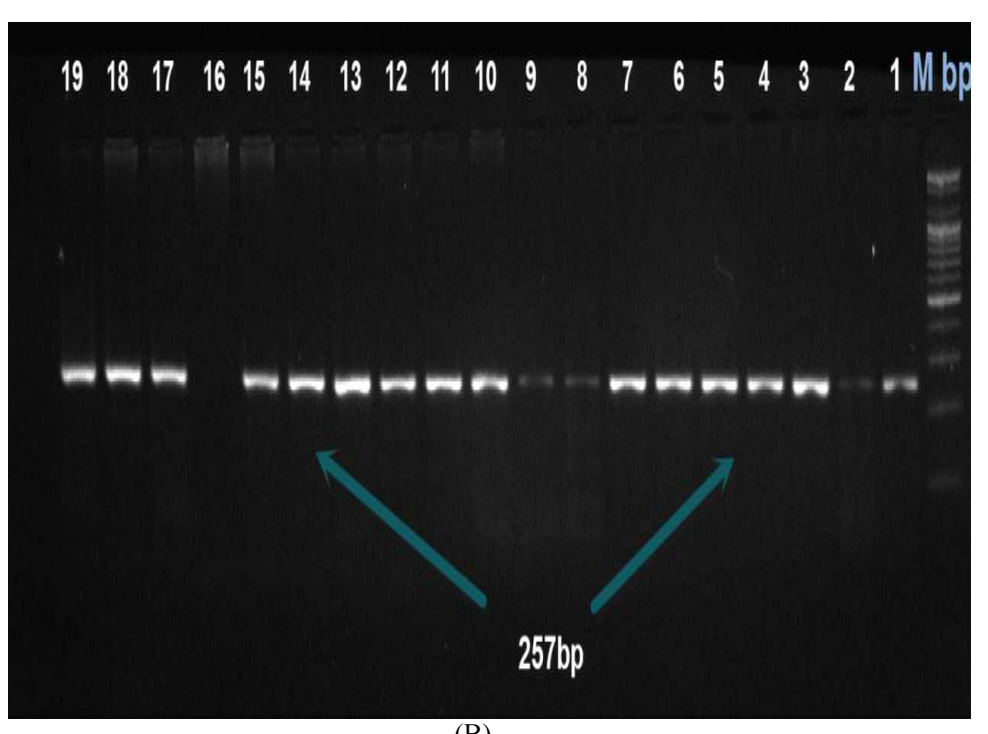

(B)

Fig. 1: Gel electrophoresis of PCR end product for rs6166 (A) Samples with the wild type of the SNP (B) samples with the mutant type of the SNP

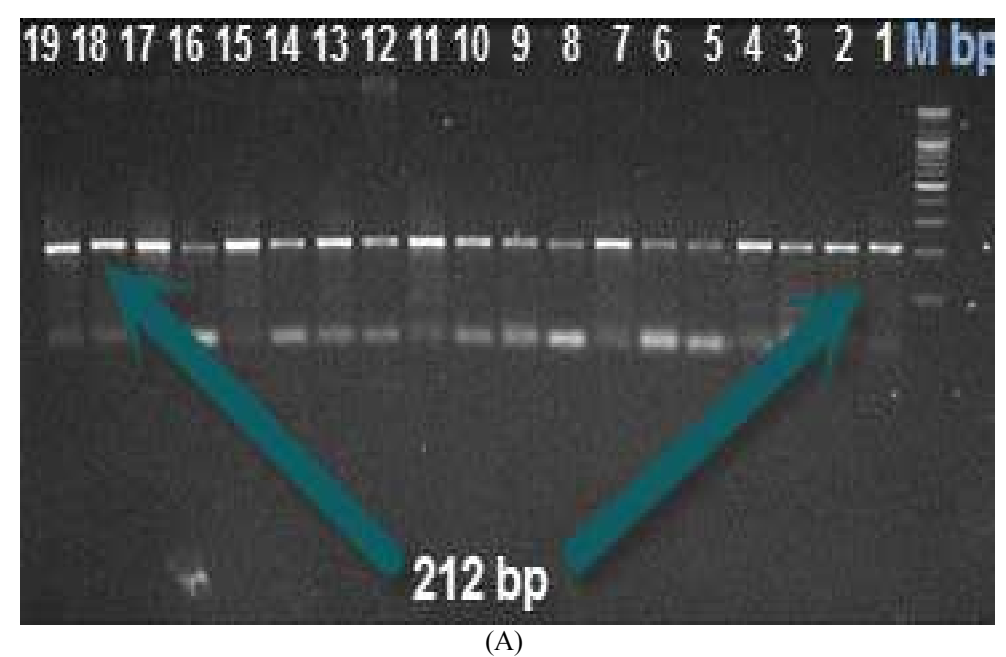




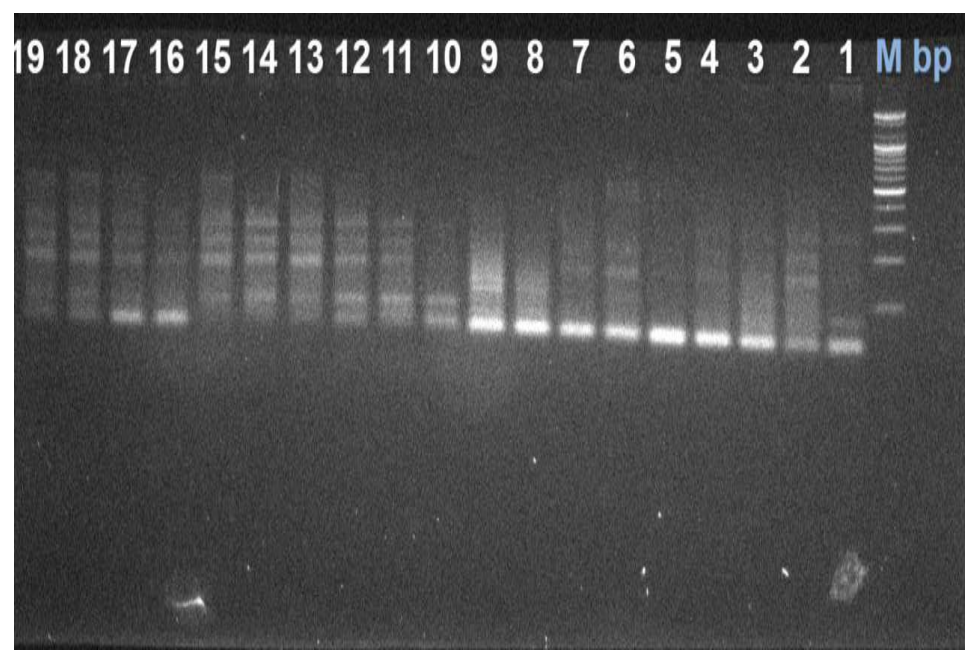

(B)

Fig. 2: Gel electrophoresis of PCR end product for rs28928870 (A) samples with the wild type of the SNP (B) samples the mutant type of the SNP

Table 2: Mean serum concentrations and standard deviation of FSH and LH

\begin{tabular}{lll} 
& FSH & LH \\
Case & Mean \pm S.D & Mean \pm S.D \\
\hline Control & $6.95 \pm 4.55 \mathrm{a}$ & $10.36 \pm 12.62 \mathrm{a}$ \\
Primary & $5.48 \pm 4.64 \mathrm{a}$ & $14.23 \pm 12.17 \mathrm{ab}$ \\
Secondary & $5.52 \pm 3.07 \mathrm{a}$ & $8.54 \pm 5.62 \mathrm{ac}$ \\
Total & $5.98 \pm 4.17$ & $11.08 \pm 10.80$ \\
\hline
\end{tabular}

Table 3: Polymorphisms detected in the LH gene

\begin{tabular}{llrc}
\hline Polymorphism & Type & Position & Frequency \\
\hline A/C & Transversion & 236 & 2 \\
A/G & Transition & 98 & 2 \\
C/T & Transition & 159 & 3 \\
G/A & Transition & 67 & 3 \\
& & 79 & 2 \\
& & 96 & 2 \\
& & 135 & 3 \\
G/C & & 230 & 3 \\
G/T & & 570 & 2 \\
\end{tabular}

Table 4: Genotype distribution of FSHR rs6166 polymorphism

\begin{tabular}{|c|c|c|c|c|c|}
\hline & \multirow[b]{2}{*}{ rs6166 } & \multicolumn{2}{|l|}{ Group } & \multirow[b]{2}{*}{ OR $(95 \% \mathrm{CI})$} & \multirow[b]{2}{*}{$P$ value } \\
\hline & & Control & Primary & & \\
\hline \multirow[t]{3}{*}{ Genotype } & $\mathrm{AA}$ & 0 & $-10 \%$ & $3.32(0.14-78.49)$ & 0.5 \\
\hline & $\mathrm{AG}$ & $-90 \%$ & $(90 \%)$ & $1.00(0.06-15.99)$ & 0.763 \\
\hline & GG & $-10 \%$ & 0 & $0.30(0.01-7.14)$ & 0.500 \\
\hline \multirow[t]{3}{*}{ Allele frequency, } & A & $-45 \%$ & $-55 \%$ & $1.49(0.44-5.03)$ & 0.376 \\
\hline & $\mathrm{G}$ & $-55 \%$ & $-45 \%$ & $0.67(0.20-2.25)$ & \\
\hline & & Control & Secondary & OR $(95 \% \mathrm{CI})$ & $P$ value \\
\hline \multirow[t]{3}{*}{ Genotype } & AA & 0 & 0 & $1.00(0.07-17.59)$ & 1.00 \\
\hline & $\mathrm{AG}$ & $-90 \%$ & $-100 \%$ & $3.0(0.13-70.59)$ & 0.526 \\
\hline & GG & $-10 \%$ & 0 & $0.33(0.01-7.84)$ & 0.526 \\
\hline \multirow[t]{2}{*}{ Allele frequency, } & A & $-45 \%$ & $-50 \%$ & $1.22(0.35-4.23)$ & 0.507 \\
\hline & $\mathrm{G}$ & $-55 \%$ & $-50 \%$ & $0.82(0.24-2.83)$ & \\
\hline
\end{tabular}


Regarding the other SNP (rs28928870) in this study, the PCR end product was electrophoresed with $2 \%$ agarose gel. The separated bands are shown in Fig. 2. This polymorphism did not show any differences between groups. Where only the wild type for this polymorphism was noticed in the three groups in current study and neither the homo mutant type nor the heterozygous were found.

\section{Discussion}

Our results for FSH were in accordance with (Al-Fahham and Al-Nowainy, 2016) who noticed that there were not any significant differences in FSH concentration among the infertile women and it was within the normal range. It also in agreement with (Digban et al., 2017) who noticed that there were not any significant differences in FSH levels between infertile and fertile women. He suggested that this could be due to primary hypogonadism particularly where low estrogen and progesterone were observed. Primary hypogonadism characterized by decreased ovarian functional activity as a result of decreased sex hormone production which could lead to fail in conceiving.

For LH, our current study agreed with (Al-Fahham and Al-Nowainy, 2016) in terms of no significant differences have been found between fertile and infertile women in LH level. However, high mean LH level in primary infertile women in our study agreed with (Odiba et al., 2014) who noticed that serum LH was higher in women with primary infertility. LH levels higher than the normal limit predict a problem in a part of the reproductive system, possibly a disorder of the mechanism of negative feedback regulation in the hypothalamus by progesterone and estrogen (Abbott et al., 2006). This explains that infertility arising from abnormal LH and FSH serum levels could be caused by a factor that is responsible for regulation or synthesis of these hormones such as GnRH which is responsible for their production, defect in pituitary gland, or even hypothalamus which controls their production by releasing GnRH (Nemeskéri et al., 1986).

Regarding LH gene and as the two polymorphisms was associated with elevated LH levels thus it might affect its structure further its binding capability to its receptor, however this require a prospective studies with larger population to detect this polymorphisms and their exact effect (Liao et al., 1998). Reported a G1502A mutation of LH $B$-subunit gene in only two infertile women that had endometriosis. An amino acid 102 substitution from Gly to Ser was the result of this mutation. Since glycine is one of the essential segments for forming the hydrophobic locales in a protein and serine has a polar side chain, the interchange of glycine with serine at amino acid 102 presents a hydrophilic power in the particle. This could influence the typical conformation and capacity of LH and thus could be involved in the pathogenesis of infertility in human. As this mutation was the only one noticed in the gene sequence that is responsible for encoding a mature $\mathrm{LH}$, it is suggested that this mutation could be associated with female infertility; especially endometriosis correlated infertility. Moreover, Du et al. (2012) found that the genotype frequency of the two point mutations Trp8Arg and Ile15Thr in the LH $\beta$-subunit gene showed significant differences between fertile and infertile women and women with both mutations showed the highest LH level. These mutations might be associated with menstrual disorders in women. This study suggests a correlation between these mutation and infertility; thus they could be a risk factor for women infertility. The mechanism of this situation could be due to the inability of binding between mutated LH and its receptor, thus reducing the biological function of $\mathrm{LH}$.

The current study conflict with (Laven et al., 2003) in terms of the predominant genotype where he found that the Ser/Ser 680 was significantly high inanovulatory infertile women and this variant was correlated with higher basal FSH levels in comparison with the two other variants Asn/Ser 680 and Asn/Asn 680, while patients in our study were have Asn/Ser 680 the predominant one. This could suggest that this Ser/Ser 680 variant in the FSHR is correlated with diminished FSH sensitivity. On the other hand, Schmitz et al. (2015) reported that there were no differences in the frequency of FSHR polymorphism Asn 680 Ser between women with endometriosis and infertility and fertile women. This could be attributed to the Brazilian population heterogeneity and due to the nature of endometriosis which is a very heterogeneous disease thus it is hard to find a polymorphism correlated with it.

In regard to the other SNP, patients and control of our study were all wild type for this polymorphism. This disagree with (Vasseur et al., 2003) who found a heterozygous $\mathrm{C} / \mathrm{T}$ mutation that result in threonine to isoleucine substitution at codon 449 in women with ovarian hyperstimulation syndrome. The binding of FSH to the mutant receptor was similar to the wild type receptor; also there were no statistically differences between the two receptors in terms of response to the recombinant follicle stimulating hormone. On the other hand, an increase in cyclic adenosine monophosphate cAMP was noticed in the mutant receptor in response to chorionic gonadotropin, while the wild receptor was insensitive except at elevated levels. This mutation expands the receptor sensitivity thus it responds to another ligand; chorionic gonadotropin. Chorionic gonadotropin fluctuation during gestation suggests that it was a trigger for the OHSS. This mutation is a highly conserved residue that is located in the serpentine domain; Thr residue position 449. The serpentine consider as a portion responsible for coupling to $G$ 
protein. It was referred that the serpentine and extracellular domain interacts and residues in domains are involved in the modulation of the binding. This mutation is probably triggers a conformational change that influence the extracellular domain.

\section{Conclusion}

Hormonal screening in infertile women is recommended; despite it is not always the main cause of the disease. Polymorphisms in specific genes that are associated with the reproductive function like FSHR and LH particularly could affect the biological activity or the sensitivity of the hormone, thus affecting ovarian activity furthermore women fertility. Asn680Ser polymorphism could have a relationship with the disease, while Thr449Ile is not. Moreover the AG genotype and A allele of Asn680Ser could be implicated in both primary and secondary infertility in the Iraqi studied women.

\section{Acknowledgment}

We aknowledge College of Science-University of Anabr for contribute in this work, also we would like to appreciate Ass. Prof. Ahmed A. Suleiman for his assistance in primer design and molecular work

\section{Author's Contributions}

All authors contribute equally in this work

\section{Ethics}

The ethical issue for this work was under the condition of ethics commity of University of Anbar

\section{References}

Abbott, D.H., V. Padmanabhan and D.A. Dumesic, 2006. Contributions of androgen and estrogen to fetal programming of ovarian dysfunction. Reproductive Biol. Endocrinol., 4: 1-8.

Al-Fahham, A.A. and H.Q. Al-Nowainy, 2016. The role of FSH, LH and prolactin hormones in female infertility. Am. J. PharmTech. Res., 6: 110-118.

Desai, S.S., B.S. Roy and S.D. Mahale, 2013. Mutations and polymorphisms in FSH receptor: Functional implications in human reproduction. Reproduction, 146: R235-R248. DOI: 10.1530/REP-13-0351

Digban, K.A., M.E. Adu, J.D. Jemikalajah and S. Adama, 2017. Hormonal profile of some infertile women in bida Nigeria. Libyan J. Med. Sci., 2: 1-5.

Du, J.W., K.Y. Xu, L.Y. Fang and X.L. Qi, 2012. Association between mutations of the luteinizing hormone $\beta$ subunit and female infertility. Molecular Med. Rep., 5: 473-476.
Ekwere, P.D., E.I. Archibong, E.E. Bassey, J.E. Ekabua and E.I. Ekanem et al., 2007. Infertility among Nigerian couples as seen in Calabar. Port. Harcourt. Med. J., 2: 35-40. DOI: 10.4314/phmedj.v2i1.38890

Filicori, M. and G.E. Cognigni, 2001. Roles and novel regimens of luteinizing hormone and folliclestimulating hormone in ovulation induction. J. Clin. Endocrinol. Metabolism, 86: 1437-1441.

Laven, J.S., A.G. Mulders, D.A. Suryandari, J. Gromoll and E. Nieschlag et al., 2003. Follicle-stimulating hormone receptor polymorphisms in women with normogonadotropic anovulatory infertility. Fertility Sterility, 80: 986-992. DOI: 10.1016/S0015-0282(03)01115-4

Liao, W.X., A.C. Roy, C. Chan, S. Arulkumaran and S.S. Ratnam, 1998. A new molecular variant of luteinizing hormone associated with female infertility. Fertility Sterility, 69: 102-106. DOI: 10.1016/S0015-0282(97)00445-7

Mafra, F.A., B. Bianco, D.M. Christofolini, Â.M. Souza and K. Zulli et al., 2010. Luteinizing hormone $\beta$ subunit gene $(L H \beta)$ polymorphism in infertility and endometriosis-associated infertility. Eur. J. Obstetr. Gynecol. Reproductive Biol., 151: 66-69. DOI: 10.1016/j.ejogrb.2010.03.022

Masoumi, S.Z., P. Parsa, N. Darvish, S. Mokhtari, M. Yavangi and G. Roshanaei, 2015. An epidemiologic survey on the causes of infertility in patients referred to infertility center in Fatemieh Hospital in Hamadan. Iran. J. Reproductive Med., 13: 513.

Matzuk, M.M. and D.J. Lamb, 2008. The biology of infertility: Research advances and clinical challenges. Nature Med., 14: 1197.

DOI: $10.1038 /$ nm.f.1895

Nemeskéri, A., A. Detta and R.N. Clayton, 1986. Hypothalamic GnRH and pituitary gonadotroph relationships during rat fetal life. Exp. Clin. Endocrinol. Diabetes, 88: 275-284. DOI: $10.1055 / \mathrm{s}-0029-1210607$

Odiba, A.S., P.E. Joshua, C.Y. Ukegbu and I. Onosakponome, 2014. Evaluation of the quantitative expression and correlation between Follicle Stimulating Hormone (FSH) and Luteinizing Hormone (LH) during follicular phase in primary infertile women of reproductive age. IOSR J. Dental Med. Sci., 13: 60-65.

Schmitz, C.R., C.A.B. de Souza, V.K. Genro, U. Matte and E. de Conto et al., 2015. LH (Trp8Arg/Ile15Thr), LHR (insLQ) and FSHR (Asn680Ser) polymorphisms genotypic prevalence in women with endometriosis and infertility. J. Assisted Reproduct. Genet., 32: 991-997. DOI: $10.1007 / \mathrm{s} 10815-015-0477-3$ 
Sharma, S., M.P. Khinchi, N. Sharma, D. Agrawal and M.K. Gupta, 2011. Female infertility: An overview. Int. J. Pharmaceutical Sci. Res., 2: 1-12.

Vasseur, C., P. Rodien, I. Beau, A. Desroches and C. Gérard et al., 2003. A chorionic gonadotropinsensitive mutation in the follicle-stimulating hormone receptor as a cause of familial gestational spontaneous ovarian hyperstimulation syndrome. New England J. Med., 349: 753-759.

DOI: $10.1056 /$ NEJMoa030065
Zegers-Hochschild, F., G.D. Adamson, J. de Mouzon, O. Ishihara and R. Mansour et al., 2009. International Committee for Monitoring Assisted Reproductive Technology (ICMART) and the World Health Organization (WHO) revised glossary on ART terminology, 2009. Fertility Sterility, 92: 1520-1524. DOI: 10.1016/j.fertnstert.2009.09.009 